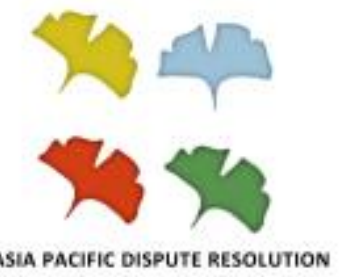

\title{
Four Suggestions on Establishing a Legal Environment for a Speedy Transformation of the Economic Development Model
}

\author{
Xiaorong Gu
}

Law Institute, Shanghai Academy of Social Sciences

\author{
APDR Working Paper Series \\ Volume 2 Number 1
}

ISSN 2371-6304

(c) (i) (9)

by Xiaorong Gu, 2017.

This article is made available as part of the As ia Pacific Dis pute Resolution

Working Paper Series and is licensed under a Creative Commons

Attribution-NonCommercial-NoDe rivatives 4.0 International License

(CC-BY-NC-ND) 


\title{
FOUR SUGGESTIONS ON ESTABLISHING A LEGAL ENVIRONMENT FOR A SPEEDY TRANSFORMATION OF THE ECONOMIC DEVELOPMENT MODEL
}

\author{
Xiaorong $\mathrm{Gu}^{1}$ \\ Law Institute, Shanghai Academy of Social Sciences (SASS)
}

When the 12th 'Five-year Plan' established as its main task to 'speed up the transformation of the economic development model', the legal system acquired a core role in this transformation. Several instruments, such as policy, economic, and administrative instruments, can transform the economic development model. However, legal instruments should be placed in an irreplaceable position among all instruments for the following reasons:

1) Legal norms and procedures are so clearly stated and informative to the participating parties that they can understand the method, duration, cost, and benefit to solve a conflict; thus, they make their choices based on full knowledge of the pros and cons. On the contrary, the other instruments are either implemented on a case by case basis, for a special occasion, or temporally; hence, they lack stability and publicity.

2) Laws are made by rigorous legislative procedures. Legal norms and procedures are the products of bargaining and compromise-making by different interest holders. The laws are made according to the principles of fairness and equality to prevent new conflicts from occurring in the resolution process of current conflicts.

3) Most of the laws are enforced by special organizations and professional staff, who are well trained and equipped, and can better protect the rights and interests of citizens.

4) Laws, once enacted, are made public to all by official gazette or social media, and therefore, are more informative, trustful, and predictable for the public.

5) The implementation of other instruments must be based on laws. Policy, economic, and administrative mechanisms must be implemented according to laws, or at least not against laws.

\footnotetext{
${ }^{1}$ Xiaorong Gu, researcher and PhD supervisor at the Law Institute of SASS and Vice President of Shanghai Law Society. This article was funded by the Asia Pacific Dispute Resolution Research (APDR) Project: Understanding Integrated Compliance with International Trade and Human Rights Standards in Comparative Perspective sponsored by the Social Sciences and Research Council of Canada (SSHRC) and by the State Social Science Major Project 'Research on Further Financial System Reform'.
} 
6) To speed up the transformation of the economic development model, China has enacted several laws and regulations, and multi-level supporting normative documents, mainly involving civil and commercial law, economic law, administrative law, criminal law and related procedural law. The substantive and procedural laws are fully established and comprehensible to be followed in practice. The law enforcement agencies and judicial institutions have been established for decades and thus become capable and experienced.

Four suggestions are proposed below for a rapid transformation of the economic development model.

\section{Advocating for and establishing a scientific concept of the rule of law}

To improve the legal environment, we must establish the following ideas guided by the rule of law. ${ }^{2}$

First, we must make a distinction between 'the protection of intellectual property rights' and 'learning and imitation' of advanced technology. Since the implementation of the 'reform and opening-up' policy for the past three decades, China's scientific and technological capacity and innovation ability have greatly improved. However, an 'innovation initiative' should still be carried out in three steps: 'learning'; 'imitation'; and 'independent innovation', either in the coastal or interior areas. The coastal developed areas possess better personnel, financial, and technical resources, and to some extent are capable to innovate independently. However, under current circumstances, these areas still cannot develop their economies without 'learning' from and 'imitation' of technologies advanced by foreign countries; less so the interior and economically under-developed areas. Therefore, small and medium-size enterprises, collegegraduate-founded enterprises, and other enterprises with more of an innovative mindset and behavior, should receive more flexible policies regarding their behaviors of 'imitating' and 'recreating' current technology. The relevant government organizations and departments generally should not forbid these kinds of behaviors for the 'protection of intellectual property rights.' Rather, they should make a clear distinction between 'infringement of intellectual property' and

\footnotetext{
2 To be specific, these ideas include the Party's leadership, overall perspective, rule of law, fairness and justice, and justice for people.
} 
'learning' and 'imitation' of technology. They should take effective measures to protect the small and medium-size enterprises,' innovation and entrepreneurship, which would protect intellectual property rights and keep these enterprises growing.

Second, we must establish the perspective of overall development. The judiciary, executive, and law enforcement organizations and their staff must take an international, modern, and strategic perspective, and perform their jobs not only according to the law, but also to consider the social effects.

Third, it is necessary to establish the idea of respecting trade customs, financial customs, and trading rules. Respect for customs and trading rules is the basic principle of commercial law. In the field of scientific and technological innovation and financial innovation, legislation is often lagging and too complicated to apply, thus the regulation of the financial market has to rely on customs and rules. Also, as some of China's financial products were borrowed from foreign countries, it is necessary to refer to the successful and mature foreign customs and rules of these countries to identify and evaluate these innovative financial products. However, we certainly cannot ignore the possible international financial risks and other economic risks coming with these products. Thus, we should fully assess the merits, reputations, pros and cons of financial practices acknowledged by the regional, industrial, and international community, and their consistency with China's national interests. We must make sure the financial rules and practices are applied safely, efficiently, and effectively, and that their applications are beneficial to our technological and financial innovation.

Fourth, we should promote and sustain innovation. The enterprise is the main body of innovation, but also the micro performer in conducting economic transformation. Innovation and creativity of the enterprise cannot be motivated and protected without surrounding them with a more relaxed legal environment. To solve the conflicts rising from innovation, judicial institutions and government departments can neither ignore the claims by arguing they are not supported by existing laws and regulations, nor be skeptical or negative to their importance. They should be supportive by actively seeking legal instruments to solve the conflicts over inappropriate and unreasonable, creative and innovative behaviors, and leave reasonable room for new innovations to grow.

Fifth, the legal instruments should be used as final protection mechanisms. Many instruments are available to encourage and protect the 'innovation initiative and transformative 
development', such as the self-discipline industry and trade associations, executive protective measures by the governments, and civil adjudication by the judicial institutions. We should exhaust all other instruments before resorting to judicial protection. The judicial procedure should start with the civil suits before the criminal suits. Mediations, arbitrations, and other alternative dispute resolution (ADR) mechanisms are preferred to adjudications.

Sixth, the principle of equal protection should be emphasized. The rights of investors, consumers, and laborers should be equally protected. The protection of intellectual property rights and the introduction and imitation of advanced science and technology should be equally protected. Furthermore, the principle of equal protection should also be applied to the innovation of enterprises of all kinds of ownership, to the relationship between the government and the enterprise, and to the relationship between the monopoly industry and ordinary industry. For example, the enterprises in the monopoly industry should assume more legal obligations, such as information disclosure, notification of standard contract terms, and risk-reporting obligations, in order to protect the legal rights and interests of the counterparty. Laws equally protect the legal rights of the enterprises in the monopoly industry.

\section{Continuing to improve the legal protection mechanism}

The legal system is closely related to the working mechanism. Laws are the legalization of mechanisms, and thus offer more stable, clarified, and continuous protection than mechanisms such as financial policy and tax deduction. However, laws cannot function effectively without the support of various mechanisms. The following mechanisms play important roles in implementing 'innovation initiative and transformative development' (hereinafter referred to as (innovation and development').

(1) Incentives for the enterprises to innovate

They mainly include lowering the criteria for establishing innovative enterprises, protecting their businesses, and simplifying various registration procedures.

Furthermore, if the Administration of Tax Collection Law provides a special tax rate for the innovative and transformative enterprises, it is a beneficial legal protection mechanism. 
(2) Identification and assessment of innovative products and behaviors

This mechanism aims to identify the effective and promising innovative products in three ways by:

a) establishing the legal procedures and institutions to conduct the identification,

b) establishing the assessment system or criteria index system,

c) establishing a special permit by issuing a certificate to acknowledge innovative products and behaviors.

The existing patent application and authorization system has these three elements and are enforceable by law. However, while most technological and financial innovations can be protected by patent laws, the innovations beyond patent law protection should be identified and protected by the three ways mentioned above.

(3) Innovation-process control and risk prevention mechanism Innovative-process control includes the following mechanisms: the main points of innovation control; qualification of innovative entrepreneur determination; intervention principle and monitoring standard; innovation distribution standard and procedure; and rights and duties of the innovation enterprises. The conduct of innovation bears some risks, and the risks greatly increase if some other factors are involved. ${ }^{3}$ To prevent these factors from happening:

a) firstly, the innovation must be conducted for making profits for clients by reducing risks, rather than pursuing the high returns for the innovative enterprises;

b) secondly, innovation must be conducted under the principle of transparency. The relevant information and risk should be disclosed to the buyers; otherwise, it is unfair to make buyers responsible for the risks. The enterprises manufacturing and selling the innovative products should be responsible for revealing the relevant information and risks pertinent to the products to the buyers.

\footnotetext{
${ }^{3}$ For example, some financial organization greatly increased the prices of financial products for high return and sold the products of high risks to clients, which triggered conflicts between the financial organization and its client.
} 
c) thirdly, the risks should be disclosed to various types of clients in various ways. Customers can be divided into professional institutions, professional individual investors, and ordinary people, and the risk of financial innovation products should be disclosed to them equally. Nevertheless, special attention should be paid to ordinary people, especially retired seniors, whereby the risk disclosure responsibility of complicated products must be borne by buyers. The financial organizations should set up procedures to protect customers and cannot mislead them. In addition, the government must conduct and monitor the risk prevention mechanisms closely, which include emergency plan for risk control; risk monitor and timely disclosure system; analysis and publication of collective innovation information; coordination between the routine activity and innovative activity in the enterprise; and most importantly the system to monitor, predict and warn about risks.

(4) The resolution and remedy for innovative crisis

As technical and financial innovations might cause high risks or even crises, such as financial crisis and others, a series of robust crisis resolution mechanisms are greatly required. These can include: crisis assessment mechanism to determine the nature, cause and harm of the crisis; crisis prepared mechanism; responsibility identification mechanism; collaborative crisis resolution mechanism and the crisis damage remedy; and compensation mechanism.

(5) Illegal innovation punishment mechanism

Illegal innovations refer to frauds under the name of innovations and other activities against legal and administrative regulations. First, innovation frauds include two types of behaviors: fraud of start-up fund, housing, and other facilities in the establishment of innovation enterprises; and fraud of patent, patent certificate and financial permit. Second, illegal innovation is the intentional violation of intellectual property rights and other legal rights. Third, it also includes the illegal innovative activities made by major mistakes or major negligence that lead to significant losses or serious social consequences. 
The five mechanisms discussed above are enforceable by the legal system. They reply to legal enforcement variously according to different circumstances. For example, the punishment mechanism must be enforced by administrative law or criminal law. The incentive mechanism is implemented mainly by policies and administrative methods. In all, the five mechanisms have been in good support by laws and regulations, and further revisions are needed to meet the new requirements, which are the focus of this article on the improvement of legal environment.

\section{Establishing and improving the fundamental informal institutions}

Laws are formal institutions, which have been mainly in place in China, while informal institutions are not yet fully established. Informal institutions involve commercial cultures and traditions, property rights cultures and traditions, and so on. They are harder to obtain but more crucial for the orderly function of market. After three decades of rapid economic growth in China, formal institutions, such as laws and regulations, are almost established but informal institutional arrangements are not fully established, such as integrity of contract and property rights. They are not only ignored by industry and even some government organs, but also barely recognized by investors. For instances, the major shareholders of the listed companies used to illegally occupy or misuse the company's property. While Hong Kong's Securities and Futures Commission (SFC) has frequently asked for immediate returns, it has often taken several years for the shareholders to return the illegally occupied property. The government should regulate these kinds of illegal behaviors not only according to laws, but also by adopting flexible strategies to make a balance between prevention of enterprise property losses and maintaining innovation motivation.

\section{Keeping in practice the traditional mechanisms which are still effective}

Traditional mechanisms are still required as supplements to formal legal systems, such as mass line, combination of mass line with legal enforcement, combination of punishing and leniency, and special campaign on special issues. Some criticized that these traditional mechanisms are outdated as they are 'temporary campaigns' and not 'permanent solutions.' However, experience has proven the traditional mechanisms to be effective. For example, the 'strike on illegal 
activities in security industry' and other special campaigns not only punish a large number of criminals, but also curb the rampant illegal security activities, and establish an effective and sustainable prevention mechanism enforced by judicial and executive institutions.

In ten to fifteen years from now, China's economy will complete its transition and update to be more market-oriented, internationalized, and open. Scientific and technological innovation will run throughout the investment, financing, trade, production, and the entire market. New governance and innovation mechanisms will upgrade accordingly, which will lead to a wide range of reforms and rapid changes in the outlook of the market, innovative services and products, trade behaviors, and so on. The shift and update of economic and industrial structure will cause new distribution of social wealth. China has established the socialist legal system with Chinese characteristics and the socialist market economy by 2010. For the next 10 to 15 years, China will shift from 'limited open' market to internationalized market, and the legal environment will play an increasingly important role during this process. 